\title{
Efficacy of NSAID (Lornoxicam) After Impacted Third-Molar Surgery With/Without Conscious Sedation: A Double-Blind Randomized Clinical Study
}

\author{
Ozkan Ozgul ${ }^{1, *}$, Selahattin Or $^{2}$ \\ ${ }^{1}$ Department of Oral and Maxillofacial Surgery, Faculty of Dentistry, Kirikkale University, Kirikkale, Turkey \\ ${ }^{2}$ Department of Oral and maxillofacial Surgery, Faculty of Dentistry, Ankara University, Ankara, Turkey \\ *Corresponding author: ozkanozgul@yahoo.com
}

\begin{abstract}
Aim: Pain and swelling following surgery for impacted third molars can be controlled by various methods. This study compared the analgesic and anti-inflammatory efficacy and tolerability of lornoxicam, aspirin and a placebo with and without conscious sedation in impacted mandibular third-molar surgery. Materials and Methods: 60 patients undergoing third-molar surgery were divided into 2 groups of conscious sedation and routine local anesthesia $(n=30)$. Both groups were divided into three subgroups $(n=10)$ that received either Lornoxicam, aspirin, or a placebo postoperatively. Results: In both the conscious sedation and local anesthesia groups, swelling reduction was significantly greater with Lornoxicam compared to aspirin and placebo $(\mathrm{p}<.05)$. Pain values were significantly lower for Lornoxicam group compared to both aspirin and placebo groups at 6,12 and 24 hours postoperatively $(\mathrm{p}<.05)$. Conclusion: Conscious sedation resulted less pain and swelling. Moreover, Lornoxicam was found to be an effective analgesic and anti-inflammatory agent for use in conjunction with oral surgery.
\end{abstract}

Keywords: conscious sedation, third molar surgery, NSAID, swelling, pain, clinical research

Cite This Article: Ozkan Ozgul, and Selahattin Or, "Efficacy of NSAID (Lornoxicam) After Impacted ThirdMolar Surgery With/Without Conscious Sedation: A Double-Blind Randomized Clinical Study." International Journal of Dental Sciences and Research, vol. 6, no. 1 (2018): 1-5. doi: 10.12691/ijdsr-6-1-1.

\section{Introduction}

Patients undergoing oral surgery may experience anxiety and discomfort that makes treatment difficult for the patient as well as the doctor and can extend the duration of surgery. [1,2] Impacted third molar surgery, the most common type of oral surgery procedure, can also cause severe inflammation and pain postoperatively. $[3,4]$

In order to secure a more comfortable operative procedure, instead of local anesthesia, the patient may be provided with conscious sedation by one of several methods, including 'inhalation conscious sedation', 'intramuscular conscious sedation' and 'intravenous conscious sedation'. The standard technique used in dentistry and oral surgery is intravenous conscious sedation with midazolam, a benzodiazepine with a short half-life of 2-3 hours. Compared to other anesthetic agents, midazolam produces a smaller hemodynamic effect, has a more rapid onset, results in less anterograde amnesia and is easier to titrate to patient response. However, when midazolam is applied intravenously, respiration depression and cardiovascular system depression is higher than it is with diazepam, the most frequently used alternative. [5]

In order to control the amount and intensity of edema, pain and trismus occurring after surgical extraction and help patients maintain their social activities, various pharmacological and/or extraction methods have been used. These include non-steroid anti-inflammatory drugs (NSAIDs), laser treatment, steroids and ultrasound. $[6,7,8]$ Lornoxicam, a member of the oxicam group of NSAIDs, is known to possess potent anti-inflammatory and analgesic properties and is widely recommended for the symptomatic treatment of pain and inflammation associated with osteoarthritis and rheumatoid arthritis as well as postoperative pain associated with gynecological, orthopedic, abdominal and dental surgery. The drug has a half-life of 3-5 hours and poor solubility in acidic conditions. $[9,10]$ There are several studies investigating the effects of conscious sedation and NSAİ on postoperative pain and swelling after third molar surgery. However there is no study of lornoxicam and conscious sedation when used together in eliminating the pain and swelling following the third molar surgery whether they would result in synergistically or not.

Our study hypothesizes that the use of lornoxicam together with conscious sedation would result in better elimination of postoperative sequels after the third molar surgeries.

The aim of this study was to evaluate the effects of Lornoxicam on pain and swelling after third-molar surgery with either conscious sedation or local anesthesia and compare this to aspirin and a placebo. 


\section{Materials and Methods}

This study was conducted as a randomized, doubleblind study, a power analysis (Power and Precision software, Biostat, Englewood, NJ, USA) was conducted to indicate sample size which indicated that detection of differences in the study could be obtained with at least 8 patients per subgroups at a power of 0.8 (alpha $=0.05)$. Thus, this study was conducted with a population of 10 patients per subgroups total of 60 young healthy adults ranging in age from 18-28 years. The study was approved by the local ethics review committee, and all patients gave their informed written consent for participation. Patients were selected based on clinical and radiographic examinations indicating Archer Class 1 or 2 vertical third molars requiring extraction. Subjects were randomly divided into 2 groups according to anesthesia procedures,

Group A: Conscious sedation $[0.06 \mathrm{mg} / \mathrm{kg}$ midazolam (Dormicum 15mg IV; Deva, Istanbul, Turkey) delivered intravenously] + local anesthesia $2.5 \%$ articaine hydrochloride (Ultracain DS; Aventis, Istanbul, Turkey).

Group B: Local anesthesia 2.5\% articaine hydrochloride (Ultracain DS; Aventis, Istanbul, Turkey) Both anesthesia groups were further divided into 3 subgroups according to post-operative medication

1: Lornoxicam (8mg, Xefo Rapid, Abdi Ibrahim, Istanbul, Turkey),

2: Aspirin, (500 mg, Bayer, Germany)

3: Placebo (Bayer, Germany).

Prior to the operation, the distance between the palpebral commissure and the mandible angle as well as the distance between the front of the auricular lobule and the labial commissure were measured. The reference points used were marked with a skin pencil to ensure standardization, and the same points were used to measure distances 48 hours post-operatively. Routine mandibular impacted third molar surgery and measurement procedures were performed by the same surgeon to ensure standardization and avoid discrepancies related to calibration. Surgeries were carried out according to a standardized technique including mucosal flap, bone removal, splitting the tooth if necessary. Duration of surgery, amount of local anesthetic solution used, and complications related to surgical procedures and analgesics were recorded.

Following surgery, patients were given 1 gr Amoxicillin (Alfoxil 1gr; Fako, Istanbul, Turkey) to prevent postoperative infection and sterile saline to maintain oral hygiene. In addition, either Lornoxicam, aspirin or a placebo (coded only as $\mathrm{X}, \mathrm{Y}$, and $\mathrm{Z}$ ) were randomly prescribed by a doctor blinded to the drug given, and patients were instructed to take the given medication at 0 (upon wound closure), 12 and 24 hours. Patients were also given follow-up forms and instructed to record the level of pain they experienced at 6, 12 and 24 hours on a Visual Analog Scale (VAS). Paracetamol 500 mg (Vermidon 500 mg; Sandoz, Istanbul, Turkey) was supplied as rescue medication for those patients who did not achieve adequate analgesia by use of the study medication. Patients were discharged from the hospital with instructions to return for control at 48 hours.

Study data was analyzed using the software package SPSS software (version 12; SPSS Inc, Chicago, IL, USA). In analyses of the data; Student $\mathrm{T}$ test was used in the comparisons of two group due to data being normally distrubuted and Anova test was used in the three group comparisons. For multiple comparisons test as post-up test for Anova; Scheffe test was chosen .05 is used as a significance level.

\section{Results}

Of the 60 patients included in the study, 34 (56.7\%) were women and $26(43.3 \%)$ were men. The mean patient age was 22.8 years (18-28). All of the patients were available for recall. None of the patients exhibited any complications or allergic reactions to the medication. None of the patients had used rescue medication. Pain and swelling scores were evaluated separately.

\subsection{Pain}

Statistical analysis of the VAS results of the sedation groups found the pain scores of the Lornoxicam subgroup to be significantly lower than the scores of both the aspirin and placebo subgroups at 6 and 24 hours $(p<.05)$ and significantly lower than the scores of the placebo subgroup at 12 hours $(\mathrm{p}<.05)$.

Among the local anesthesia groups, the VAS scores of the Lornoxicam subgroup were significantly lower than the scores of both the aspirin and placebo subgroups at 6 , 12 and 24 hours $(p<.05)$. In addition, the aspirin subgroup had significantly lower pain scores than the placebo subgroup at 6 and 12 hours $(\mathrm{p}<.05)$. (Table 1 - Table 2$)$

Table 1. Within the columns, siginificant differences are represented by different superscript capital letters $(P<.05)$.Within rows, significant differences are represented by different superscript small letters $(\mathrm{P}<.05)$

\begin{tabular}{|c|c|c|c|}
\hline & \multicolumn{3}{|c|}{ Concious Sedation } \\
\hline & lornoxicam & aspirin & placebo \\
\hline 6th hour & $9,5^{\mathrm{A}, \mathrm{a}}$ & $27,9^{\mathrm{A}, \mathrm{b}}$ & $30,1^{\mathrm{A}, \mathrm{b}}$ \\
\hline 12th hour & $15,0^{\mathrm{B}, \mathrm{a}}$ & $30,9^{\mathrm{A}, \mathrm{b}}$ & $33,1^{\mathrm{A}, \mathrm{b}}$ \\
\hline 24th hour & $2,0^{\mathrm{B}, \mathrm{a}}$ & $26,7^{\mathrm{A}, \mathrm{b}}$ & $28,0^{\mathrm{A}, \mathrm{b}}$ \\
\hline
\end{tabular}

Table 2. Within the columns, siginificant differences are represented by different superscript capital letters $(P<.05)$.Within rows, significant differences are represented by different superscript small letters $(\mathrm{P}<.05)$

\begin{tabular}{|c|c|c|c|}
\hline & \multicolumn{3}{|c|}{ Local anesthesia } \\
\hline & lornoxicam & aspirin & placebo \\
\hline 6th hour & $19,6^{\mathrm{A}, \mathrm{a}}$ & $23,7^{\mathrm{A}, \mathrm{a}}$ & $23,8^{\mathrm{A}, \mathrm{a}}$ \\
\hline 12th hour & $20,5^{\mathrm{A}, \mathrm{a}}$ & $25,0^{\mathrm{A}, \mathrm{a}}$ & $34,7^{\mathrm{A}, \mathrm{a}}$ \\
\hline 24th hour & $12,0^{\mathrm{B}, \mathrm{a}}$ & $34,8^{\mathrm{B}, \mathrm{b}}$ & $44,6^{\mathrm{B}, \mathrm{b}}$ \\
\hline
\end{tabular}

When all the groups are compared with each other statistical differences are noted. CS/lornoxicam group showed statistically lower pain scores than all other groups at 6th, 12th and 24th hours $(\mathrm{p}<.05)$. Also LA/lornoxicam subgroup showed statistically lower pain then other subgroups for all time periods $(\mathrm{p}<.05)$. There was no difference amongst $\mathrm{CS} /$ Aspirin, LA/aspirin, CA/placebo and LA/placebo at 6th and 12th hour $(\mathrm{p}>.05)$. However LA/placebo group showed statistically higher pain scores then all other groups at 24 th hour $(\mathrm{p}<.05)$ (Figure 1). 


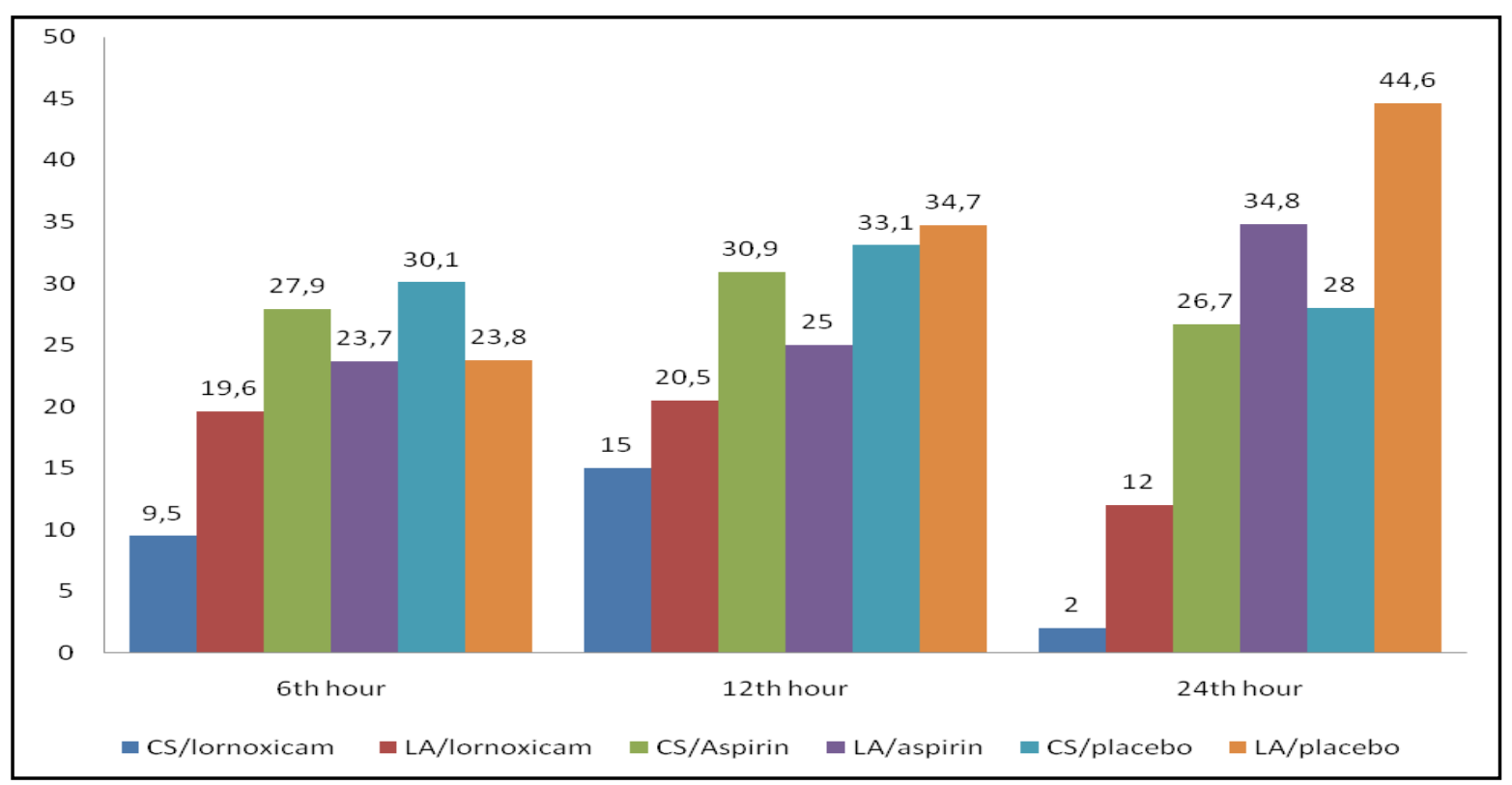

Figure 1. Boxplot display shows the average pain scores for lornoxicam, aspirin and placebo groups for main groups of conscious sedation and local anesthesia

\subsection{Swelling}

According to preoperative and postoperative face measurements, amounts of swelling were significantly higher for the local anesthesia groups when compared to the conscious sedation groups $(\mathrm{p}<.05)$. Furthermore, swelling was significantly higher for the sedation/placebo subgroup when compared to the sedation/Lornoxicam and sedation/aspirin subgroups $(p<.05)$. Swelling was also significantly higher for the local anesthesia/placebo subgroup when compared to the local anesthesia/aspirin $(p<.05)$ and local anesthesia/Lornoxicam $(p<.05)$ subgroups and for the local anesthesia/aspirin subgroup when compared to the local anesthesia/Lornoxicam $(\mathrm{p}<.05)$ subgroup. (Figure 2).

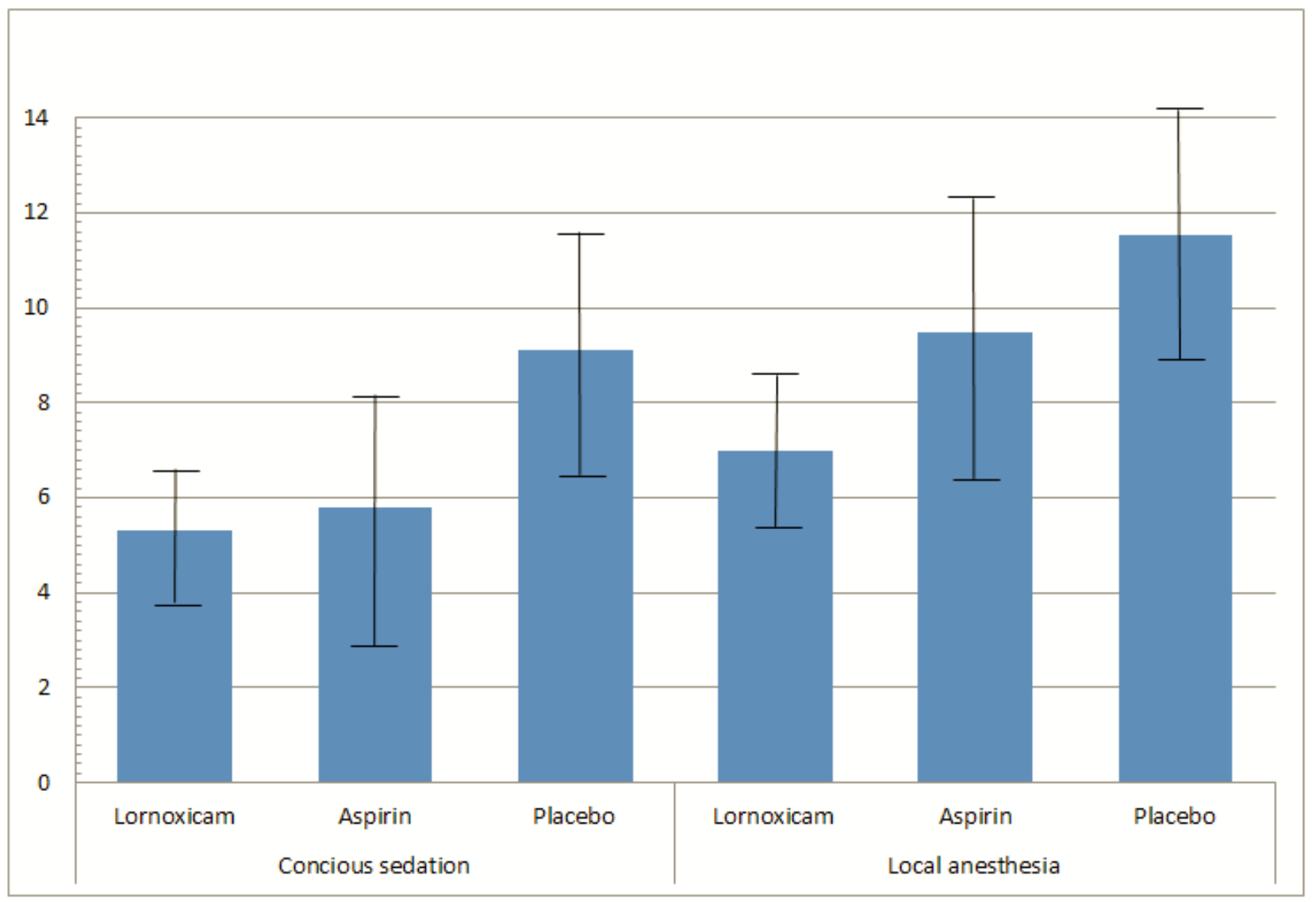

Figure 2. Boxplot display shows the average swelling scores for lornoxicam, aspirin and placebo groups for main groups of conscious sedation and local anesthesia 


\section{Discussion}

As with other surgical procedures, extraction of an impacted third molar is followed by a period of discomfort that includes pain, swelling and trismus. Extensive research has been conducted in an attempt to alleviate or even totally eliminate such problems by using different extraction methods or varying postoperative medical treatment; however, an adequate solution has yet to be found. [11-16]

Postoperative complications such as pain, swelling, trismus and bleeding vary depending upon the medical condition and age of the patient. [17,18,19,20] In order to prevent differences arising from such factors and ensure standardization, the population of this study was comprised of healthy, young individuals who had fully completed their growth and who had impacted teeth of similar severity.

A double-blind study by Bonnin [12] investigating pain thresholds of volunteer subjects found individuals administered midazolam $(0.07 \mathrm{mg} / \mathrm{kg})$ as intravenous conscious sedation had significantly lower pain scores when compared to individuals administered physiologic serum without sedation. Another randomized, doubleblind study conducted by Coulthard and Rood [21] similarly found that volunteers provided with intravenous conscious sedation with midazolam $(0.07 \mathrm{mg} / \mathrm{kg})$ during painful operations reported less pain compared to those given serum only. Both studies concluded that conscious sedation raises pain thresholds, making it easier for patients to tolerate surgery.

Ong et al [2] compared postoperative pain levels of subjects provided with conscious sedation with midazolam and those receiving local anesthesia only for extraction of an impacted wisdom tooth. While patients receiving conscious sedation reported lower postoperative pain scores, they also required analgesics for a longer period of time postoperatively than the patients receiving local anesthesia only.

Lustenberg et al [22] compared the analgesic efficacy and tolerability of a pre-emptive/post-surgical 4-day regimen of oral ibuprofen $(400 \mathrm{mg})$ with that of Lornoxicam (8mg) and concluded that both drugs were equally effective in managing pain after third-molar extraction.

Zor et al [10] also examined the efficacy of pre-emptive Lornoxicam on analgesia following surgical removal of mandibular third molars. The authors reported that $8 \mathrm{mg}$ Lornoxicam delivered intravenously 25 minutes before surgery was more effective in controlling pain than the same amount of Lornoxicam delivered intravenously following surgery.

As authors knowledge this study is the first to investigate the effects of conscious sedation in conjunction with different analgesics and compared them to patients only receiving local anesthesia with the same analgesics.

When patients receiving conscious sedation in examined, no abnormal changes were observed in patients' vital findings, and none of the patients reported any nausea or anxiety in line with previous studies. When compared to patients receiving local anesthesia only, those receiving conscious sedation with midazolam reported less discomfort during surgery and faster recovery, with less postoperative pain and edema.

In the present study results also showed that pain scores of patients receiving conscious sedation did not statistically differ from only local anesthesia group when the used analgesic were aspirin or placebo. However when patients received conscious sedation with lornoxicam pain scores were statistically lower than local anesthesia with lornoxicam. However LA/lornoxicam group also showed lower pain scores then CS/aspirin CS/placebo LA/aspirin and $\mathrm{LA} /$ placebo.

\section{Conclusion}

In Conclusion, the study results clearly indicated that patients who received Lornoxicam after third-molar surgery with conscious sedation had the best results in terms of pain and swelling control. Lornoxicam was also found to be much more effective for pain reduction in general. Further studies are needed to compare the effectiveness of conscious sedation with different types of analgesics in terms of pain and swelling reduction following extraction surgery on impacted third-molars.

Minimizing the discomfort after third molar surgery is an important factor for patients who undergone the surgery. This study demonstrated that conscious sedation resulted in less pain and swelling compared to local anesthesia alone which increases patients comfort. Moreover, Lornoxicam was found to be an effective analgesic and anti-inflammatory agent for use in conjunction with oral surgery.

\section{Statement of Competing Interests}

The authors claim to have no financial interest, either directly, or indirectly, in the products or information listed in the article.

\section{References}

[1] Malamed, S.F, Conscious sedation and general anesthesia techniques and drugs used in dentistry, Anesth prog., 33, 176-178, 1986.

[2] Ong, K.S., Seymour, A., Tan, H, Sedation with midazolam leads to reduced pain after dental surgery, Anesth analg.,98, 1289-1293, 2004.

[3] Archer, W.H, Oral and Maxillofacial Surgery, fifth ed., Saunders Company Philadelphia, 1975.

[4] Amin, M.M., Laskin, D.M, Prophylactic use of indomethacin for prevention of postsurgical complications after removal of impacted third molars. Oral Surg Oral Med Oral Pathol., 55, 448-451, 1983.

[5] Kay, B., Total intravenous anaesthesia. Elsevier Science Publishers, Amsterdam. 1991.

[6] Bagan, J.V., Lopez, J.S., Valencia, E, Clinical comparison of dexketoprofen trometamol and dipyrone in postoperative dental pain, J clin pharmacol,. 38, 55-64, 1998.

[7] Björnsson, G.A., Haanaes, H.R., Skoglund, L.A, Naproxen 500 $\mathrm{mg}$ bid versus acetaminophen $1000 \mathrm{mg}$ qid: effect on swelling and other acute postoperative events after bilateral third molar surgery, J. Clin pharmacol.,43, 849-858, 2003.

[8] Spilka, C.J, The placebo of corticosteroids and antihistamines in oral surgery, Oral Surg Oral Med Oral Pathol., 14, 1034-1042, 1961. 
[9] Mowafi, H.A., Elmakarim, E.A., Ismail, S., Al-Mahdy, M., ElSaflan, A.E., Elsaid, A.S, Intravenous lornoxicam is more effective than paracetamol as a supplemental analgesic after lower abdominal surgery: a randomized controlled study, World $J$ Surg.,36, 2039-2044, 2012

[10] Zor, Z.F., Isık. Z., Cetiner S, Efficacy of preemptive lornoxicam on postoperative analgesia after surgical removal of mandibular third molars. Oral Surg Oral Med Oral Pathol Oral Radiol, 117, 27-31, 2014

[11] López-Ramírez, M., Vílchez-Pérez, M.A., Gargallo-Albiol, J., Arnabat-Domínguez, J., Gay-Escoda, C, Efficacy of low-level laser therapy in the management of pain, facial swelling, and postoperative trismus after a lower third molar extraction: a preliminary study, Laser Med Sci., 27, 559-566, 2012

[12] Colarado-Bonnin, M., Valmeseda-Castellon, E., Berini-aytes, L., Gay-Escoda, C, Quality of life following lower third molar removal, Int. J oral Maxillofac Surg., 35, 343-347, 2004.

[13] Penarrocha, M., Sanchis, J.M., Saez, U., Gay, C., Bagán J.V, Oral hygiene and postoperative pain after mandibular third molar surgery. Oral surg. Oral med. Oral pathol. Oral. Radiol. Endod., 92, 260-264, 2001.

[14] Jimenez-martinez, E., Gasco-garcia. C., Arrieta-blanco. J.J., Gomez del Torno, J., Bartolome Villar, B, Study of the analgesic efficacy of dexketoprofen trometamol $25 \mathrm{mg}$ vs. Ibubprofen 600 $\mathrm{mg}$ after their administration in patients subjected to oral surgery, Med oral., 9, 138-148, 2004.
[15] Seymour, R.A., Blair, G.S., Wyatt, F.A, Postoperative dental pain and analgesic efficacy. Part 1, Br J Oral Surg., 21, 290-297, 1983.

[16] Macgregor, A.J., Addy, A, Value of penicilin in the prevention of pain swelling and trismus and following the removal of ectopic mandibular third molars. Int J Oral Surg., 9, 166-171, 1980.

[17] Coulthard, P., Haywood, D., Tai, M.A., Jackson-Leech, D., Pleuvry, B.J., Macfarlane, T.V, Treatment of postoperative pain in oral and maxillofacial surgery. Br J Oral Maxillofac Surg., 38, 588-592, 2000.

[18] Lau, S.L., Chow, R.L., Yeung, R.W., Samman, N, Preemptive ibuprofen arginate in third molar surgery: a double-blind randomized controlled crossover clinical trial. Aust Dent J., 54, 355-360, 2009.

[19] Markovic, A.B., Todorovic, L, Postoperative analgesia after lower third molar surgery: contribution of the use of long-acting local anesthetics, low-power laser, and diclofenac. Oral Surg Oral Med Oral Pathol Oral Radiol Endod. 102, 4-8, 2006.

[20] Seymour, R.A., Meechan, J.G., Blair, G.S, An investigation into postoperative pain after third molar surgery under local analgesia. Br J Oral Maxillofac Surg., 23, 410-418, 1985.

[21] Coulthard, P., Rood, J.P, An investigation of the effect of midozolam on the pain experience. Br J Oral Maxillofac Surg., 30 248-251, 1992.

[22] Lustenberger, F.D., Grätz, K.W., Mutzbauer, T.S, Efficacy of ibuprofen versus lornoxicam after third molar surgery: a randomized, double-blind, crossover pilot study, Oral maxillofacial Surg., 15, 62-67, 2011. 